\title{
Pulse pressure variation shows a direct linear correlation with tidal volume in anesthetized healthy patients
}



\begin{abstract}
Background: The settings of mechanical ventilation, like tidal volume (VT), occasionally need to be adjusted in the process of anesthesia for some special reasons. The aim of this study was therefore to assess the relationship between pulse pressure variations (PPVs) in different settings of VT in anesthetized healthy patients under mechanical ventilation.

Methods: Sixty nine ASA I-II patients scheduled for gastrointestinal surgery under general anesthesia were included in this prospective study. All the patients were ventilated at a VT of 6,8 or $10 \mathrm{ml} / \mathrm{kg}$ (predicted body weight) with no positive end expiratory pressure (PEEP) in a random order after intubation. PPV, mean arterial blood pressure, and other hemodynamic and respiratory parameters were recorded in each VT setting respectively after Partial Pressure of EndTidal Expiration Carbon Dioxide $\left(\mathrm{PetCO}_{2}\right)$ maintained between $30 \mathrm{mmHg}$ and $40 \mathrm{mmHg}$ by changing Respiratory Rate (RR) before incision.

Results: The values of PPV at different settings of VT showed a tight correlation between each other ( 6 vs. $8 \mathrm{ml} / \mathrm{kg}: r=0.97, P<0.0001 ; 6$ vs. $10 \mathrm{ml} / \mathrm{kg}: r=0.95, P<0.0001 ; 8$ vs. $10 \mathrm{ml} / \mathrm{kg}: r=0.98, P<0.0001$, respectively).

Conclusion: There is a direct linear correlation between PPVs at different tidal volumes in anesthetized ASA I-II patients. PPV in any of the $3 \mathrm{VT}$ settings $(6,8$ or $10 \mathrm{ml} / \mathrm{kg})$ can deduce that in any other 2 settings. Further studies are needed to explore the effect of intraoperative confounders for this knowledge to be clinically applied.

Trial registration: NCT01950949, www.clinicaltrials.gov, July 26, 2013.

Keywords: Pulse pressure variation, Tidal volume, Blood pressure, Volume, Mechanical ventilation

Abbreviations: ARDS, Acute respiratory distress syndrome; ASA, American Society of Anesthesiologists; BIS, Bispectral index; HR, Heart rate; MAP, Mean arterial pressure; PEEP, Positive end expiratory pressure; PetCO $_{2}$, Partial pressure of end-tidal expiration carbon dioxide; Pmean, Mean airway pressure; Ppeak, Peak airway pressure; PPV, Pulse pressure variation; RR, Respiratory rate; SW, Stroke volume variation; VT, Tidal volume
\end{abstract}

\section{Background}

Adequate fluid administration can increase cardiac output, improve microcirculatory perfusion, avoid tissue edema and shorten hospital stay in patients [1-4]. Pulse pressure variation has recently been recommended as an effective predictor of fluid responsiveness in patients receiving mechanical ventilation $[5,6]$. Previous studies

\footnotetext{
* Correspondence: mwd1962@sina.cn

${ }^{\dagger}$ Equal contributors

'Anesthesiology and Operation Center, Chinese PLA General Hospital, 28

Fuxing Road, Haidian District, Beijing 100853, China

Full list of author information is available at the end of the article
}

have demonstrated the excellent predictive power of PPV on fluid responsiveness just at a VT higher than $8 \mathrm{ml} / \mathrm{kg}$, the predictive accuracy of PPV at a low VT remains uncertain [7-9]. In addition, a series of studies suggested to carry out the lung-protective ventilation strategies at a low VT and low positive end-expiratory pressure both in critically ill and patients undergoing elective operation [10-12]. Similar to stroke volume variation (SVV), PPV value could increase proportionally in the same cardiovascular state in anesthetized mongrel dogs as VT increases [13]. And there is a significant linear correlation between PPVs at a VT of 6 and $8 \mathrm{ml} / \mathrm{kg}$ in patients with severe sepsis and septic shock 
after resuscitation [14]. However, there have been few studies revealing the actual relationship between PPVs in various different VT settings in patients without cardiopulmonary diseases. Sometimes, in order to maintain the appropriate $\mathrm{PetCO}_{2}$ level in some special operations (laparoscopic surgery, robotic surgery, cerebral surgery, etc.), ventilator settings, especially the VT in the volumecontrolled ventilation, vary during the course of a surgical procedure [15]. Therefore, the objective of this study was to examine the relationship between the values of PPV under different VT settings in anesthetized patients without cardiopulmonary disorder.

\section{Methods}

\section{Patients}

This study was approved by the Ethical Committee of the Chinese PLA General Hospital (Registration No. 20111124028, Chinese PLA General Hospital, Beijing 100853, China, chairperson Kun-lun $\mathrm{He}$ ) and was registered at www.clinicaltrials.gov (ID: NCT01950949). Informed written consent was obtained from each patient. Adult patients (aged 1860 years, ASA I or II) scheduled for elective gastrointestinal surgery (open or laparoscopic approach) were enrolled prospectively between July 2013 and March 2014. Patients with suspected acute respiratory distress syndrome, cardiovascular diseases, neurological disease, liver and renal function abnormal, or diabetes mellitus, and those whose predicted body weight did not match actual body weight were excluded. All the patients received oral sodium phosphate solution the night before the surgery prescribed by the surgeons for gastrointestinal preparation.

\section{Procedure}

Once in the operating room, an infusion of Lactated Ringer's solution was started at $4 \mathrm{ml} \cdot \mathrm{kg}^{-1} \cdot \mathrm{h}^{-1}$ through the 18G upper limb venous trocar. Anesthesia was induced using midazolam (0.04 mg.kg $\left.{ }^{-1}\right)$, fentanyl $\left(3 \mu \mathrm{g} \cdot \mathrm{kg}^{-1}\right)$, propofol (1.5-2.5 mg. $\left.\mathrm{kg}^{-1}\right)$ and rocuronium $\left(0.6 \mathrm{mg} . \mathrm{kg}^{-1}\right)$, and maintained by an intravenous infusion of propofol to keep the Bispectral index (Aspect Bis Monitor XP) between 40 and 60. After tracheal intubation, a $20 \mathrm{G}$ artery catheter was inserted into the left radial artery and connected to a bed-side monitor (Philips Intellivue MP50). Pressure transducers were zeroed at the mid-axillary level to atmospheric pressure. All patients were ventilated at a VT of 6,8 or $10 \mathrm{ml} / \mathrm{kg}$ (predicted body weight) with $50 \%$ oxygen with air without PEEP in a random order and successively for $3 \mathrm{~min}$ in each setting. During this period, the respiratory rate was adjusted to maintain an $\mathrm{PetCO}_{2}$ between 30 and $40 \mathrm{mmHg}$. PPV, arterial blood pressure, heart rate (HR), peak airway pressure (Ppeak), mean airway pressure (Pmean), RR, $\mathrm{PetCO}_{2}$ and $\mathrm{BIS}$ value were recorded $3 \mathrm{~min}$ after VT change while the vital signs were stable. Then the parameters under the three settings of VTs were recorded. In the case that PPV value was larger than $13 \%$ at a VT of $8 \mathrm{ml} / \mathrm{kg}, 10 \mathrm{ml} / \mathrm{kg}$ of $6 \%$ hydroxyethyl starch solution (HES 130/0.4; VOLUVEN; Fresenius Kabi, Stans, Switzerland) would be given to these patients (defined as subgroup) for volume expansion over $15 \mathrm{~min}$. And then the next round of recording was conducted in a new cycling of these three VT settings. All the parameters were obtained before skin incision in the supine position. During these periods, $5 \mathrm{mg}$ ephedrine was administered when SAP lowered below $90 \mathrm{mmHg}$, and this case would be eliminated.

\section{Statistical analysis}

Statistical analyses were performed using SPSS 13.0 for Windows (SPSS, Chicago, IL, USA). Normally distributed data were presented as mean \pm standard deviation. Non-normally distributed data were presented as median (25-75 \% interquartile range). Hemodynamic data and respiratory parameters at various VT were compared using ANOVA and Student-Newman-Keuls test. Pearson's linear correlation was used to analyze the degree of association between variables. $P$-values less than 0.05 were considered statistically significant.

\section{Results}

Sixty nine patients without heart and pulmonary complications undergoing selected abdominal operation were enrolled in this study. Patient characteristics were presented in Table 1 . And 27 patients whose PPV values were larger than $13 \%$ at the VT of $8 \mathrm{ml} / \mathrm{kg}$ under the initial three VT settings were considered as the subgroup.

To maintain the PetCO2 between 30 and $40 \mathrm{mmHg}$, the respiratory rate declined when the VT went up from $6 \mathrm{ml} / \mathrm{kg}$ to $8 \mathrm{ml} / \mathrm{kg}$ or $10 \mathrm{ml} / \mathrm{kg}$. Meanwhile, the peak airway pressure and mean airway pressure increased along with VT (Fig. 1).

There was no significant difference in the mean blood pressure and heart rate between different VT settings. However, PPV increased progressively when the VT changed from $6 \mathrm{ml} / \mathrm{kg}$ to $8 \mathrm{ml} / \mathrm{kg}$ or $10 \mathrm{ml} / \mathrm{kg}$ (Fig. 2).

\section{Table 1 Patients' characteristics}

\begin{tabular}{ll}
\hline Variable & Global \\
\hline Gender $(\mathrm{m} / \mathrm{f})$ & $43 / 26$ \\
Age $(\mathrm{y})$ & $46.46(10.43)$ \\
Height $(\mathrm{cm})$ & $168.20(7.30)$ \\
Actual Body Weight $(\mathrm{kg})$ & $62.88(7.56)$ \\
BMl $\left(\mathrm{kg} / \mathrm{m}^{2}\right)$ & $22.18(1.78)$ \\
Predicted Body Weight $(\mathrm{kg})$ & $62.61(8.43)$ \\
\hline
\end{tabular}

Data are presented as mean (SD) $B M I$ body mass index 




A significant linear correlation between PPVs at a VT of $6 \mathrm{ml} / \mathrm{kg}$ and $8 \mathrm{ml} / \mathrm{kg}$ was found in the study $(r=0.97)$, and the linear regression equation was $Y=1.1691+1.2277 \mathrm{X}$. There was also a significant linear correlation between PPVs at a VT of $6 \mathrm{ml} / \mathrm{kg}$ and $10 \mathrm{ml} / \mathrm{kg}(r=0.94)$, and the linear regression equation was $Y=1.5888+1.5549 \mathrm{X}$.
Moreover, a significant linear correlation was observed between PPVs at a VT of $8 \mathrm{ml} / \mathrm{kg}$ and $10 \mathrm{ml} / \mathrm{kg}(r=0.98$; linear regression equation, $Y=-0.044+1.2795 \mathrm{X}$ ) (Fig. 3). The patients in the subgroup (27 patients who received volume expansion) showed a significant linear correlation between the PPV values under the three VT settings

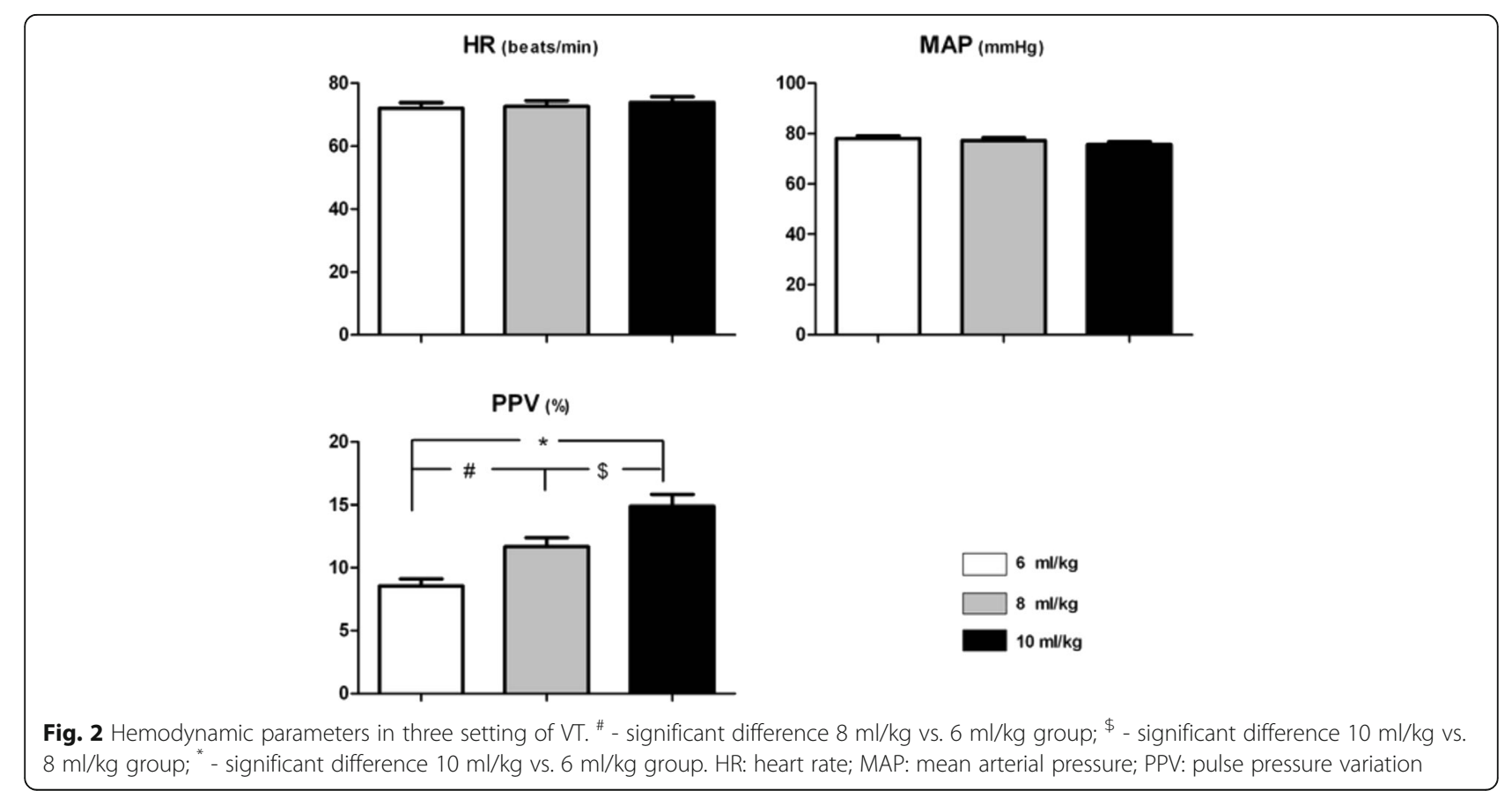



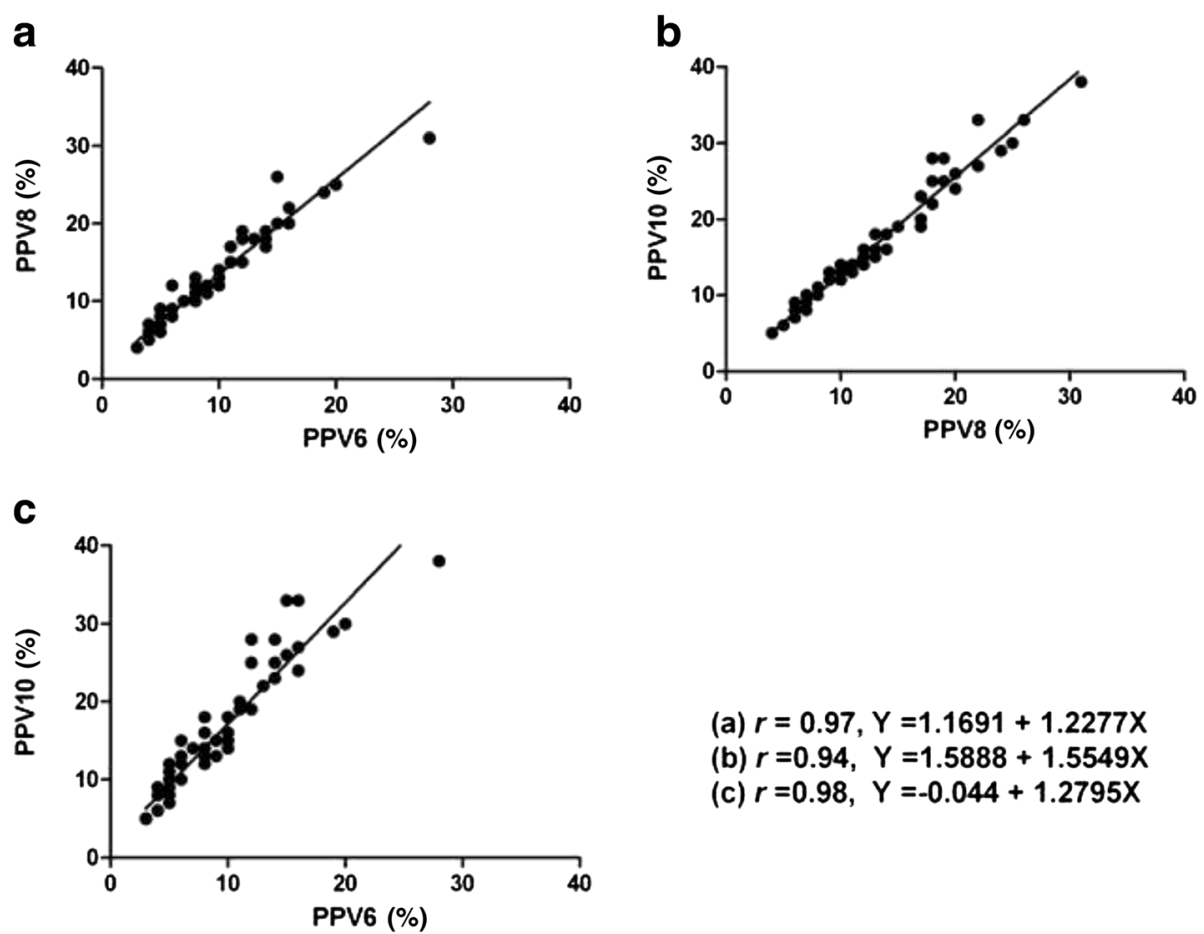

(a) $r=0.97, Y=1.1691+1.2277 X$
(b) $r=0.94, Y=1.5888+1.5549 X$
(c) $r=0.98, Y=-0.044+1.2795 X$

Fig. 3 Linear relationship between PPVs under the VT of 6,8 and $10 \mathrm{ml} / \mathrm{kg}$ before volume expansion. PPV6: pulse pressure variation at a VT of $6 \mathrm{ml} / \mathrm{kg}$; PPV8: pulse pressure variation at a VT of $8 \mathrm{ml} / \mathrm{kg}$; PPV10: pulse pressure variation at a VT of $10 \mathrm{ml} / \mathrm{kg}$. Equation (a) represented the linear correlation between PPV6 and PPV 8. Equation (b) represented the linear correlation between PPV8 and PPV 10. Equation (c) represented the linear correlation between PPV6 and PPV10

(PPV6 vs. PPV8: $r=0.96$; PPV6 vs. PPV10: $r=0.92$; PPV8 vs. PPV10: $r=0.98)$. The correlation coefficient of the subgroup was similar with the initial observations (Fig. 4).

\section{Discussion}

The main findings of our study were that PPV increased progressively as the VT increased in the same cardiovascular status and volume status, and that there was a significant linear correlation between any two values of PPV when VT was 6,8 or $10 \mathrm{ml} / \mathrm{kg}$ respectively.

To explore the relationship of PPVs at various VT, we enrolled patients without respiratory and cardiovascular dysfunctions in our investigation, The reason why ARDS patients were excluded was that their pathological changes might weaken the transmission of the driving pressure during mechanical ventilation $[16,17]$. Another reason was clinically most of the intraoperative patients were ASA I-II without cardiopulmonary diseases. In order to avoid confounding from abdominal insufflations, abdominal retractors, interference with the sympathetic nervous system, etc, we obtained the parameters before skin incision [18-20].

Previous reports showed that tidal volume was the main factor influencing PPV during mechanical ventilation [7, 21]. For many years, a high tidal volume (10-15 $\mathrm{ml} / \mathrm{kg}$ ) was recommended to recruit collapsed lung tissue and improve ventilation perfusion mismatch $[22,23]$. But recent studies alerted people the harm of high tidal volume ventilation and showed that low tidal volume ventilation (range of $6-8 \mathrm{ml} / \mathrm{kg}$ ) may be helpful not only in the treatment of ARDS but also in the prevention of ARDS, atelectasis, and lung infections in patients without ARDS [24-28]. Therefore, the VT of 6,8 and $10 \mathrm{ml} / \mathrm{kg}$, which were used frequently in our clinical work, were selected in this clinical trial.

Recently, Freitas et al. found that PPV could accurately predict fluid responsiveness in septic patients ventilated at a lower VT, and there was a significant linear correlation between PPVs at a VT of $6 \mathrm{ml} / \mathrm{kg}$ and $8 \mathrm{ml} / \mathrm{kg}$ $(r=0.92)$ [14]. The similar linear correlation between PPVs in these two VT settings was also obtained in our study, but the correlation coefficient was higher $(r=0.97)$. This discrepancy could be explained by the different subjects of the two studies. In Freitas's study, all the patients suffered from ARDS, whose mean pulmonary arterial pressure was larger than $25 \mathrm{mmHg}$; however, the enrolled patients in our study had no pulmonary inflammation or circulation system disease [14]. Moreover, we found that there was a significant linear correlation between PPVs at a VT of $6 \mathrm{ml} / \mathrm{kg}$ and $10 \mathrm{~mL} / \mathrm{kg}(r=0.94)$, and that the correlation was also significant between PPVs at a VT of $8 \mathrm{ml} / \mathrm{kg}$ and 

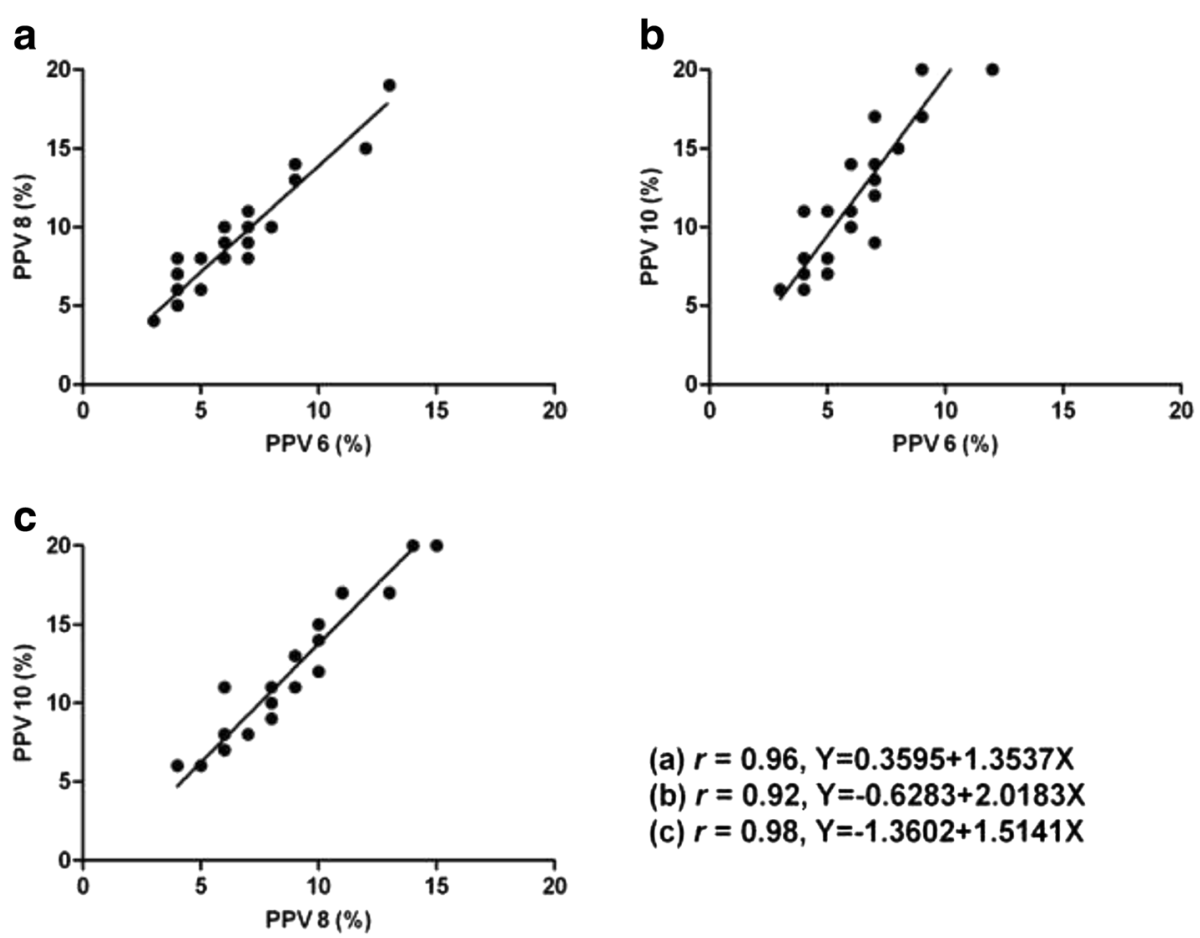

(a) $r=0.96, Y=0.3595+1.3537 \mathrm{X}$

(b) $r=0.92, Y=-0.6283+2.0183 X$

(c) $r=0.98, Y=-1.3602+1.5141 X$

Fig. 4 Linear relationship between PPVs under the $V T$ of 6,8 and $10 \mathrm{ml} / \mathrm{kg}$ after volume expansion. PPV6: pulse pressure variation at a VT of $6 \mathrm{ml} / \mathrm{kg}$; PPV8: pulse pressure variation at a VT of $8 \mathrm{ml} / \mathrm{kg}$; PPV10: pulse pressure variation at a VT of $10 \mathrm{ml} / \mathrm{kg}$. Equation (a) represented the linear correlation between PPV6 and PPV 8. Equation (b) represented the linear correlation between PPV6 and PPV 10. Equation (c) represented the linear correlation between PPV8 and PPV10.

$10 \mathrm{ml} / \mathrm{kg}(r=0.98)$. Also, based on the subgroup analysis, the high correlation coefficient of different PPV values at different VT existed no matter what the patients' volume status was.

Regressive equations could be drawn on the basis of the Pearson's correlation analysis, (Figs. 3 and 4). In accordance to the regressive equations, the PPV at any other VT can be calculated based on the PPV obtained with the real-time monitor at a given VT. For example, if the PPV was $5 \%$ at a VT of $6 \mathrm{ml} / \mathrm{kg}$, based on the equation $Y=1.1691+1.2277 \mathrm{X}$, the PPV was $7 \%$ at a VT of $8 \mathrm{ml} / \mathrm{kg}$ and it reached $9 \%$ at the VT of $10 \mathrm{ml} / \mathrm{kg}$ according to the equation $Y=1.5888+1.5549 \mathrm{X}$. In addition, when the values of PPV in different settings of VT were compared, we found that the bigger the PPV was, the greater the difference between any two values of PPV (Fig. 5).

Theoretically, if such regressive equations are applied in bedside monitors as a program, the values of PPV under any other VT setting in the current volume status can be calculated based on the real-time PPV value under a given VT and will be shown in real time on the monitors. It will be helpful in clarifying the volume status and thus deciding the demand of the fluid administration for patients ventilated with a low VT by deducing their PPV values under VT of 8 or $10 \mathrm{ml} / \mathrm{kg}$.
In our study, there were some limitations to consider. The foremost was that we only assessed the relationship between the PPVs in the most commonly used VT settings $(6,8$ and $10 \mathrm{ml} / \mathrm{kg})$ in patients without cardiopulmonary disorder. Secondly, the parameters were only obtained before surgical procedure. Thirdly, the subgroup in the study

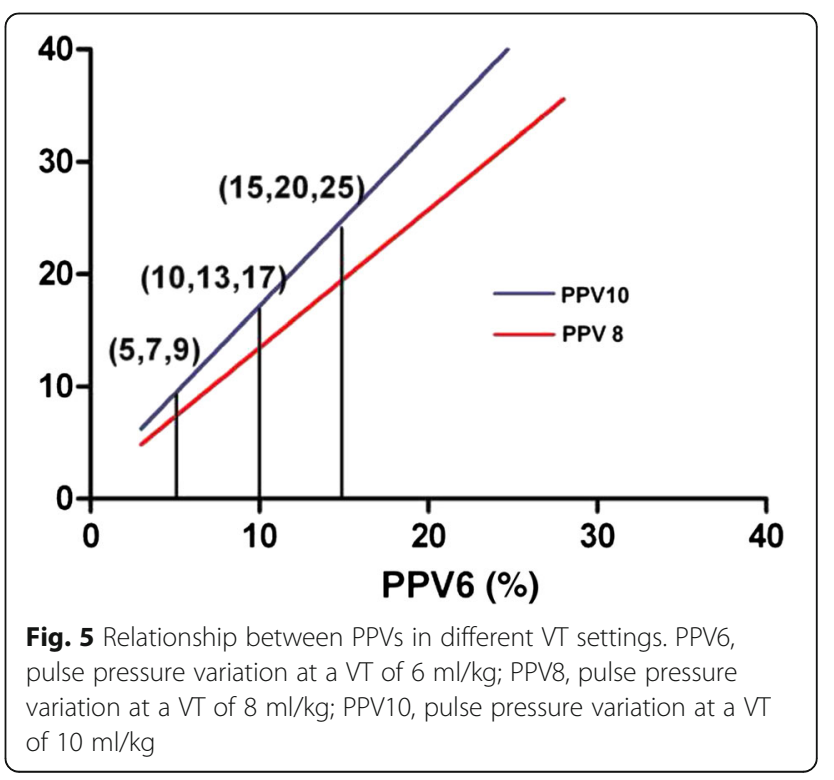


only covered a portion of the initially enrolled patients. Under such circumstances, it is suggested that a series of new clinical trials be designed to evaluate the relationship between the PPV values in healthy humans under other VT settings (eg 5,7 or $9 \mathrm{ml} / \mathrm{kg}$ ) or in the patients with heart and lung diseases (eg ARDS, cardiac insufficiency, etc.). We are planning to conduct clinical trials to evaluate the relationship between the PPV values under different VT during operation, especially during some special types of surgeries like laparoscopic surgeries.

\section{Conclusions}

In this study we have demonstrated that there was a direct linear correlation between any two values of PPV when the VT was 6,8 or $10 \mathrm{ml} / \mathrm{kg}$ respectively. In addition, we have developed the regressive equations for the calculation of PPV values under different settings of VT. Using these regressive equations, we can calculate the PPV in another setting of VT based on the PPV at a given VT.

\section{Acknowledgements}

We thank Dr. Jing Liu, Dr. Long-he Xu (Anesthesiology and Operation Center, Chinese PLA General Hospital, Beijing, China.), Dan Feng (Section of Medical Statistics, Chinese PLA General Hospital, Beijing, China.), Lin-lin Jiang (The people's liberation army medical school, Beijing, China.) and Xiao-fei Ye (The second military medical school, Shanghai, China) for their kind help during the study implementation and manuscript writing.

\section{Funding}

This study was supported by Chinese PLA general hospital nursery fund of science and technology innovation (Award Number:14KMM35, Grant Recipient: Yi Liu).

\section{Availability of data and materials}

Data will not be shared. The patent application do not allow the raw data to the public.

\section{Authors' contributions}

All authors have made substantive intellectual contributions to the manuscript. LY participated in the design of the study and in the clinical trials, performed data analysis, and drafted the manuscript. $\sqcup$ helped perform data analysis. MW conceived the study and finalized the manuscript. YW participated in the design of the study and in the clinical trials. FQ helped revising the manuscript and drawing graph. WM participated in the clinical trials and acquisition of data. QJ participated in the design of the study and help draft the manuscript. All authors read and approved the final manuscript.

\section{Competing interests}

The authors declare that they have no competing interests.

\section{Consent for publication}

Not applicable.

\section{Ethics approval and consent to participate}

This study was approved by the Ethical Committee of the Chinese PLA General Hospital (Registration No. 20111124-028, Chinese PLA General Hospital, Beijing 100853, China, chairperson Kun-lun He) and each participant provided written informed consent.

\section{Author details}

'Anesthesiology and Operation Center, Chinese PLA General Hospital, 28 Fuxing Road, Haidian District, Beijing 100853, China. ${ }^{2}$ Department of Anesthesiology, Beijing Tongren hospital, Capital Medical University, Beijing
100041, China. ${ }^{3}$ Graduate School, Xuzhou Medical College, Xuzhou 221004, Jiangsu Province, China.

Received: 11 September 2015 Accepted: 24 August 2016

Published online: 08 September 2016

\section{References}

1. Wang P, Zhou M, Rana MW, Ba ZF, Chaudry IH. Differential alterations in microvascular perfusion in various organs during early and late sepsis. Am J Physiol. 1992;263(1 Pt 1):G38-43.

2. Astiz ME, Rackow EC. Septic shock. Lancet. 1998;351(9114):1501-5.

3. Rivers E, Nguyen B, Havstad S, Ressler J, Muzzin A, Knoblich B, Peterson E, Tomlanovich M, Early Goal-Directed Therapy Collaborative G. Early goaldirected therapy in the treatment of severe sepsis and septic shock. N Engl J Med. 2001;345(19):1368-77.

4. Hollenberg SM, Ahrens TS, Annane D, Astiz ME, Chalfin DB, Dasta JF, Heard SO, Martin C, Napolitano LM, Susla GM, et al. Practice parameters for hemodynamic support of sepsis in adult patients: 2004 update. Crit Care Med. 2004;32(9):1928-48.

5. Bliacheriene F, Machado SB, Fonseca EB, Otsuke D, Auler Jr JO, Michard F. Pulse pressure variation as a tool to detect hypovolaemia during pneumoperitoneum. Acta Anaesthesiol Scand. 2007;51(9):1268-72.

6. Marik PE, Cavallazzi R, Vasu T, Hirani A. Dynamic changes in arterial waveform derived variables and fluid responsiveness in mechanically ventilated patients: a systematic review of the literature. Crit Care Med. 2009;37(9):2642-7.

7. De Backer D, Heenen S, Piagnerelli M, Koch M, Vincent JL. Pulse pressure variations to predict fluid responsiveness: influence of tidal volume. Intensive Care Med. 2005;31(4):517-23.

8. Vallee F, Richard JC, Mari A, Gallas T, Arsac E, Verlaan PS, Chousterman B, Samii K, Genestal M, Fourcade O. Pulse pressure variations adjusted by alveolar driving pressure to assess fluid responsiveness. Intensive Care Med. 2009;35(6):1004-10.

9. Muller L, Louart G, Bousquet PJ, Candela D, Zoric L, de La Coussaye JE, Jaber S, Lefrant JY. The influence of the airway driving pressure on pulsed pressure variation as a predictor of fluid responsiveness. Intensive Care Med. 2010;36(3):496-503.

10. Choi G, Wolthuis EK, Bresser P, Levi M, van der Poll T, Dzoljic M, Vroom MB, Schultz MJ. Mechanical ventilation with lower tidal volumes and positive end-expiratory pressure prevents alveolar coagulation in patients without lung injury. Anesthesiology. 2006;105(4):689-95.

11. Putensen C, Theuerkauf N, Zinserling J, Wrigge H, Pelosi P. Meta-analysis: ventilation strategies and outcomes of the acute respiratory distress syndrome and acute lung injury. Ann Intern Med. 2009;151(8):566-76.

12. Guldner A, Kiss T, Serpa Neto A, Hemmes SN, Canet J, Spieth PM, Rocco PR, Schultz MJ, Pelosi P, Gama de Abreu M. Intraoperative protective mechanical ventilation for prevention of postoperative pulmonary complications: a comprehensive review of the role of tidal volume, positive end-expiratory pressure, and lung recruitment maneuvers. Anesthesiology. 2015;123(3):692-713.

13. Mesquida J, Kim HK, Pinsky MR. Effect of tidal volume, intrathoracic pressure, and cardiac contractility on variations in pulse pressure, stroke volume, and intrathoracic blood volume. Intensive Care Med. 2011;37(10): 1672-9.

14. Freitas FG, Bafi AT, Nascente AP, Assuncao M, Mazza B, Azevedo LC, Machado FR. Predictive value of pulse pressure variation for fluid responsiveness in septic patients using lung-protective ventilation strategies. Br J Anaesth. 2013;110(3):402-8.

15. Miller RD. Miller's anesthesia. 7th ed. Philadelphia: Churchill Livingstone/ Elsevier; 2010.

16. Jardin F, Genevray B, Brun-Ney D, Bourdarias JP. Influence of lung and chest wall compliances on transmission of airway pressure to the pleural space in critically ill patients. Chest. 1985;88(5):653-8.

17. Mallat J, Lemyze $M$, Thevenin D. Ability of respiratory pulse pressure variation to predict fluid responsiveness in ARDS: still an unanswered question? Crit Care. 2011;15(3):432. author reply 432.

18. Gouvea G, Diaz R, Auler L, Toledo R, Martinho JM. Evaluation of the pulse pressure variation index as a predictor of fluid responsiveness during orthotopic liver transplantation. Br J Anaesth. 2009;103(2):238-43.

19. Hoiseth LO, Hoff IE, Myre K, Landsverk SA, Kirkeboen KA. Dynamic variables of fluid responsiveness during pneumoperitoneum and laparoscopic surgery. Acta Anaesthesiol Scand. 2012;56(6):777-86. 
20. van Lavieren M, Veelenturf J, Hofhuizen C, van der Kolk M, van der Hoeven J, Pickkers P, Lemson J, Lansdorp B. Dynamic preload indicators decrease when the abdomen is opened. BMC Anesthesiol. 2014;14:90.

21. Oliveira RH, Azevedo LC, Park M, Schettino GP. Influence of ventilatory settings on static and functional haemodynamic parameters during experimental hypovolaemia. Eur J Anaesthesiol. 2009;26(1):66-72.

22. Bendixen HH, Hedley-Whyte J, Laver MB. Impaired Oxygenation in Surgical Patients during General Anesthesia with Controlled Ventilation. A Concept of Atelectasis. N Engl J Med. 1963;269:991-6.

23. Marini JJ. Evolving concepts in the ventilatory management of acute respiratory distress syndrome. Clin Chest Med. 1996;17(3):555-75.

24. Amato MB, Barbas CS, Medeiros DM, Magaldi RB, Schettino GP, Lorenzi-Filho G, Kairalla RA, Deheinzelin D, Munoz C, Oliveira R, et al. Effect of a protectiveventilation strategy on mortality in the acute respiratory distress syndrome. N Engl J Med. 1998:338(6):347-54.

25. Petrucci N, lacovelli W. Ventilation with lower tidal volumes versus traditional tidal volumes in adults for acute lung injury and acute respiratory distress syndrome. Cochrane Database Syst Rev. 2003;3, CD003844.

26. Weingarten TN, Whalen FX, Warner DO, Gajic O, Schears GJ, Snyder MR, Schroeder DR, Sprung J. Comparison of two ventilatory strategies in elderly patients undergoing major abdominal surgery. Br J Anaesth. 2010;104(1):16-22.

27. Futier E, Constantin JM, Paugam-Burtz C, Pascal J, Eurin M, Neuschwander A, Marret E, Beaussier M, Gutton C, Lefrant JY, et al. A trial of intraoperative low-tidal-volume ventilation in abdominal surgery. N Engl J Med. 2013;369(5):428-37.

28. Serpa Neto A, Nagtzaam L, Schultz MJ. Ventilation with lower tidal volumes for critically ill patients without the acute respiratory distress syndrome: a systematic translational review and meta-analysis. Curr Opin Crit Care. 2014;20(1):25-32.

\section{Submit your next manuscript to BioMed Central and we will help you at every step:}

- We accept pre-submission inquiries

- Our selector tool helps you to find the most relevant journal

- We provide round the clock customer support

- Convenient online submission

- Thorough peer review

- Inclusion in PubMed and all major indexing services

- Maximum visibility for your research

Submit your manuscript at www.biomedcentral.com/submit

C) Biomed Central 